Tropical Journal of Pharmaceutical Research July 2015; 14 (7): 1299-1303

ISSN: $1596-5996$ (print); 1596-9827 (electronic)

(C) Pharmacotherapy Group, Faculty of Pharmacy, University of Benin, Benin City, 300001 Nigeria.

All rights reserved.

Available online at http://www.tjpr.org

Original Research Article

http://dx.doi.org/10.4314/tjpr.v14i7.25

\title{
Assessing Consumer Preference using Community Pharmacy Preference Evaluation Questionnaire (ComPETe): A Pilot Survey in a Malaysia City
}

\author{
Shazwani Shaharuddin ${ }^{1}$, Ashikin Zamaludin², Rosnani Hashim², Muhammad \\ Abdul Hadi ${ }^{3}$ and Long Chiau Ming ${ }^{1,4 *}$ \\ ${ }^{1}$ Faculty of Pharmacy, Universiti Teknologi MARA (UiTM), Puncak Alam, ${ }^{2}$ Faculty of Pharmacy, Cyberjaya University College of \\ Medical Sciences (CUCMS), ${ }^{3}$ School of Pharmacy, Monash University Malaysia, Sunway, Selangor, ${ }^{4}$ Brain Degeneration and \\ Therapeutic Group, Pharmaceutical and Life Sciences CoRE, UiTM, Shah Alam, Malaysia
}

*For correspondence: Email: shazwani.s@gmail.com, long@puncakalam.uitm.edu.my; Tel: +603-32584775

Received: 20 February 2015

Revised accepted: 8 June 2015

\begin{abstract}
Purpose: To assess the consumer preference for community pharmacy (CP) for filling prescription, and purchasing over-the-counter (OTC) and health products among customers frequenting eight departmental stores located in a Malaysian city.

Method: A cross-sectional study was conducted in the city of Wakaf Bharu, Kelantan, Malaysia. A total of 400 respondents in the area were randomly selected to participate in the 14-item Community Pharmacy Preference Evaluation Questionnaire (ComPETe). The results were then subjected to data analysis.

Results: A total of 198 respondents returned the questionnaire but only 120 respondents completely filled in them. Majority of the respondents was between the age of 18 and 30 years (42.4\%), female $(55.0 \%)$ and married (66.7\%). Most of them (90.8\%) agreed that location is an important criterion for choosing a CP. About 62 and $56 \%$ of the respondents went to the same preferred CP and at least once a month, respectively. Interestingly, customers with a monthly income of $\angle R M 1000$ (equivalent to USD 280) and married were more likely to visit the same preferred CP $(p<0.05)$. More than half of the respondents preferred heavily subsidized medical treatment for minor ailments from government healthcare institutions. For OTC products, preference among consumers was almost the same among CPs and local stores. With regard to health supplements and screening test kits, most respondents preferred to go to CPs.

Conclusion: The respondents showed variability in their preference for CPs. The findings about consumer preference for CPs and health products should facilitate the process of launching a successful CP establishment.
\end{abstract}

Keywords: Consumer satisfaction, Community pharmacy preference, Prescription filling, Over-thecounter products, Financial management

Tropical Journal of Pharmaceutical Research is indexed by Science Citation Index (SciSearch), Scopus, International Pharmaceutical Abstract, Chemical Abstracts, Embase, Index Copernicus, EBSCO, African Index Medicus, JournalSeek, Journal Citation Reports/Science Edition, Directory of Open Access Journals (DOAJ), African Journal Online, Bioline International, Open-J-Gate and Pharmacy Abstracts

\section{INTRODUCTION}

In business and marketing studies, consumer preference survey (CPS) is commonly used to gather information on local customers' preferences and needs. This is important because early feedback from customers would help to ensure the continuous growth of a business and to entice them to keep patronizing the business. The CPS can be conducted by 
including regulars that frequent a certain part of a commercial venue or residents living in the surrounding area [1]. It is especially important to perform CPS locally because consumer preferences are not always the same. The importance of conducting a market survey is to ensure that the services and products offered can meet consumers' needs.

For instance, a survey was conducted in the suburb of New South Wales, Australia to determine if consumer preferences for health services have changed from 1989 to 2002 [2]. A similar survey was also conducted in the urban slums in Dhaka and adjacent rural areas to evaluate the key determinants of healthcare service users' preferences. Interestingly, pharmacy was voted as the main healthcare service in the study conducted in Dhaka. Unfortunately however, residents reported that pharmacy operators offered substandard services, and that regular training and additional supports were much needed in Dhaka [3].

On a similar note, a CPS exploring the attributes of pharmacy choice for people with chronic conditions was conducted in Australia. The researchers had concluded that the profile of pharmacy in Australia as a healthcare destination needed enhancement through concerted efforts. They suggested that pharmacy staffs should focus the service towards patients in order to ensure that clients' needs are entertained [4].

Fully government-funded healthcare institutions remain the most popular choice among Malaysians. In 2014, public sector hospital admissions and outpatient treatment were 69.3 $\%$ and $93.4 \%$, respectively [5]. This shows that the Malaysian general public prefers to receive outpatient treatment at government clinics or hospitals because only a nominal fee of the Malaysian currency, RM 1 (equivalent to USD 0.28 ) is charged whereas senior citizens are automatically entitled to free treatment, inclusive of consultation and medication supply [6].

In addition, the number of pharmacy schools has increased from 3 in 2000 to more than 18 in 2014. The sharp increase in the number of pharmacists in the job market directly caused a rise in the number of community pharmacies (CPs). For example, in 2006 there were 270 registered CPs in Malaysia. The number went up from 445 in 2009 to 663 in 2010 and then achieved its maximum at 794 in 2011 [6].
Two main antagonistic factors, that is having more CPs and a very low-cost public healthcare system complicate the successful operation of a $\mathrm{CP}$. In order to ensure a sustainable CP business, it is essential to conduct a proper CPS on a regular basis. This is crucial to monitor clients' personal, social and economic factors that can influence decision making regarding their purchase. To the best of our knowledge, no published research has evaluated the perspective of Malaysian consumers' preferences for CPs. The aim of this study was to determine the consumer preference for CPs as well as for health products.

\section{EXPERIMENTAL}

\section{Study design and data collection}

This study was a cross-sectional survey using a convenience sampling method conducted in Wakaf Bharu, a city situated in the state of Kelantan, Malaysia. A pilot-tested selfadministered questionnaire was distributed as an exit survey at 8 departmental stores selected randomly in Wakaf Bharu between August and September, 2012. Convenience sampling was used to recruit participants. Consumers who cannot read the Malay language and were below 18 years of age were excluded. The sample size was determined using the formula presented by Cochran [7]. For a $95 \%$ confidence level, the sample size was 330. Participation in the survey was voluntary. Three data collectors were trained in advance in terms of the survey's intention and how to recruit respondents. The study protocol was approved by the research ethics committee established at the authors' university (Cyberjaya University College of Medical Sciences, CUCMS).

\section{Study instrument}

Our tool, Community Pharmacy Preference Evaluation Questionnaire (ComPETe), was developed based on literature review [8-11]. The questionnaire was piloted to 12 respondents who were not included in the final survey. Face and content validity were performed among 4 senior lecturers from the Department of Clinical Pharmacy, Faculty of Pharmacy, CUCMS.

The final questionnaire consisted of two parts: demographic data and assessment of consumers' preferences. In the demographic section, consumers were asked to provide their gender, age, marital status, number of children, employment status, monthly income and level of education. Section two contained 14 items about 
consumers' criteria when choosing a CP, frequency of visiting a $\mathrm{CP}$, specific $\mathrm{CP}$ that the respondent patronizes (loyalty towards a particular CP), preference for consultation for feverish symptoms and over-the-counter products, and type of service/product sought. Respondents were asked to tick one of the various suggested options ('yes', 'no' or 'not sure') appropriate to each item. Cronbach's alpha value was calculated collectively as well as for individual sections with results indicating that the questionnaire had good internal consistency.

\section{Data analysis}

Data were coded using Statistical Package for Social Science (SPSS) version 16.0 (SPSS Inc, Chicago, IL). Descriptive analysis was performed by calculating numbers and percentages. Some of the questions had multiple answers for the respondents to choose from; therefore the sum total of percentages is not always a $100 \%$. Pearson's chi-squared test was used to calculate the association between consumers' characteristics and preferences for CPs with a $p$ $<0.05$ value considered to be statistically significant.

\section{RESULTS}

\section{Socio-demographics and general knowledge}

Out of the 400 questionnaires sent, 198 were returned (response rate of $49.5 \%$ ). At the end of the study period, 120 respondents were included in the final analysis. A total of 78 respondents were excluded due to incomplete responses to the questionnaire. The socio-demographic characteristics of the respondents are shown in Table 1. Further statistical analysis showed that there was no significant difference between loyalty with consumers' age and gender.

Among the 120 respondents, $90.8 \%$ of the respondents agreed that the primary criterion when choosing a CP was location. Meanwhile, among the respondents, $85 \%$ agreed that the other important factor was the services offered by the CP. Product assortment was ranked as number 3 which comprised of $84.0 \%$ from the total respondents followed by price (78.4 \%), membership program (62.5\%) and staff $(60.8$ $\%)$. Further investigations showed that $74(61.7$ $\%)$ visited a specific CP while 46 (38.3 \%) did not, which indicates a high loyalty towards the preferred CP. The majority of participants, 67 (55.8\%) reported visiting the $\mathrm{CP}$ at least once per month. Customers with a monthly income of less than RM 1000 (equivalent to USD 300) and married were more likely to visit the same preferred CP $(p<0.05)$.

Table 1: Demographic profile of the respondents

\begin{tabular}{|c|c|c|}
\hline Variable & $\mathbf{N}$ & $\%$ \\
\hline \multicolumn{3}{|l|}{ Gender } \\
\hline Male & 54 & 45.00 \\
\hline Female & 66 & 55.00 \\
\hline \multicolumn{3}{|l|}{ Age (years) } \\
\hline $18-30$ & 51 & 42.50 \\
\hline $31-40$ & 22 & 18.30 \\
\hline $41-50$ & 30 & 25.00 \\
\hline $51-60$ & 12 & 10.00 \\
\hline$>60$ & 5 & 4.20 \\
\hline \multicolumn{3}{|l|}{ Marital status } \\
\hline Single & 37 & 30.80 \\
\hline Married & 80 & 66.70 \\
\hline Widowed & 3 & 2.50 \\
\hline \multicolumn{3}{|l|}{ No. of children } \\
\hline None & 49 & 40.80 \\
\hline 1 & 12 & 10.00 \\
\hline 2 & 2 & 1.70 \\
\hline 3 & 7 & 5.80 \\
\hline 4 & 15 & 12.50 \\
\hline 5 & 17 & 14.20 \\
\hline$>5$ & 18 & 15.00 \\
\hline \multicolumn{3}{|l|}{ Educational level } \\
\hline Secondary school & 87 & 72.50 \\
\hline Diploma & 2 & 1.70 \\
\hline University/degree & 30 & 25.00 \\
\hline Masters & 1 & 0.80 \\
\hline \multicolumn{3}{|l|}{ Employment status } \\
\hline None & 45 & 37.50 \\
\hline Self-employed & 33 & 27.50 \\
\hline Government & 21 & 17.50 \\
\hline Private & 22 & 18.30 \\
\hline \multicolumn{3}{|c|}{ Monthly income (RM) } \\
\hline$<1000$ & 50 & 41.70 \\
\hline $1001-3000$ & 21 & 17.50 \\
\hline $3001-5000$ & 2 & 1.70 \\
\hline $5001-10000$ & 2 & 1.70 \\
\hline
\end{tabular}

(Exchange rate RM1 equivalent to USD 0.28)

Furthermore, $74(61.7 \%)$ of the respondents preferred to go to the hospital or clinic when having a fever compared to $36(30.0 \%)$ that went to the $\mathrm{CP}$. The rest of the 10 respondents preferred self-medication. On the other hand, health products and services that the respondents sought from the CP were prescribed medication $(92.5 \%)$ as well as the point of care blood tests and counseling (83.3\%). For OTC medications such as paracetamol, most respondents $(74.2 \%)$ showed equal preference between local stores and CPs. According to the survey, most consumers preferred going to the $\mathrm{CP}$ for their health supplements and screening tests such as blood glucose test with a finding of $62(51.7 \%)$ and $89(74.0 \%)$ respectively. For products such as dental care and cosmetics, 104 $(86.7 \%)$ of the respondents preferred to purchase from local stores. 


\section{DISCUSSION}

The highest rated criterion for choosing a $\mathrm{CP}$ was its location. Most Malaysians rely on their car to travel around thus a location with easily accessible car park is important. Furthermore, the logistic aspect is worth considering due to increasing fuel price and the busy lifestyle of full time working parents. However, our study does not probe further the consumers' interpretation of a good location for a CP such as within their neighborhood, a shopping complex or hospital. Services, product assortments and pricing were highly valued while membership program and staffs were less regarded as the factor affecting the choice of a CP. Therefore, the service provided by the pharmacist, translated as his or her knowledge and competency, are crucial because it will affect their consumers' decision on purchasing a product or medication.

Surprisingly, a study carried out in the neighboring country, Singapore showed that more than half of the participants never consulted community pharmacists for advice on management of minor ailments such as cold, gastric discomfort, diarrhea or constipation. Instead, majority self-medicated and will only consult healthcare professionals when selfmedication is not effective [12]. However with the advent of more CP outlets and health promotion, it is very likely the situation has changed now. As a comparison, majority of the public in Jordan would ask for pharmacists' advice when the condition is not serious enough to see a doctor [13].

Interestingly, our study showed that the price of products was rated fourth over six criteria in choosing a CP; in our opinion, this shows that people were willing to pay more to get a better and faster relief for their illness as they do not mind to purchase in a CP instead of heading to a public hospital or clinic to get their medications, which as mentioned earlier only costs RM 1 . In Malaysia, medicines dispensed by the government are mostly generic while in the private sector it can be either generic or innovator medicines [14]. Meanwhile, a study on customers' willingness to pay had been carried out for certain medications [15]. Pharmacists can potentially use result from willingness to pay studies to gauge the price range of services and products that is acceptable by consumers, as there could be a limit to the amount consumers can afford or are willing to spend for their medications. Majority of the respondents visited the CP at least once a month. This correlates well with the frequency of $\mathrm{CP}$ visits cited in a study done in Northern Ireland [16]. Three quarters of the participants visited the $\mathrm{CP}$ at least once a month and interestingly females who were 60 years above visited the CP on a more regular basis than males or other age groups. That study showed that there is a potentially new niche market for female geriatric customers. Meanwhile, our findings also indicated that the respondents had a certain degree of loyalty towards the same CP. Pharmacists can improvise marketing strategies by providing discount cards to retain and monitor purchasing trends of their customers.

Based on this study, it was found that most of the locals relied on government hospitals and clinics for treatment of minor ailments. The obvious reason was these public healthcare institutions provide treatment and medication at a minimum nominal fee of RM 1. The government-subsidized healthcare service is very popular because the patient gets to see a medical doctor without appointment and could receive medication for free. Nevertheless, for those who can afford to buy their own medication or prefer a specific brand for certain medications, they would rather go to a private clinic or $\mathrm{CP}$ to avoid the long waiting time in government healthcare centers. Another product highly sought after by consumers in CPs is OTC. Health supplements and screening kits need to be in stock to meet the demand of customers. As for other products such as dental care, the CPs could display some necessity items such as medicated toothpaste and gum care products in order to serve as a one stop shopping point to provide convenience for the consumers.

\section{Limitations of the study}

The small number of respondents, which led to a relatively low response rate, might limit the generalizability of the findings. As a suggestion for future research, a study with a larger sample size could be carried out to compare the differences between the purchasing patterns in urban and rural consumers, education levels, income earned, gender and age. All data were self-reported and might be subject to bias. Another limitation was data collection (survey of respondents) was only done once, and there was no follow-up after a period, to determine if consumer preference changed significantly change. As such, a further study is recommended whereby this study could be repeated over a duration of several months to determine any change in customer preferences.

\section{CONCLUSION}

This study has explored the issues of consumer 
preferences towards CPs based on the local population of Wakaf Bharu. Location would be the most important criterion in visiting a CP. Local patrons display high loyalty towards their preferred CP. This study suggests that consumers may not be fully aware of the roles of $\mathrm{CPs}$ in public health screening, as a drug information center or a place to seek treatment for minor ailments.

\section{ACKNOWLEDGEMENT}

This work was supported by Research Acculturation Grant Scheme (RAGS), Malaysia (no. RAGS/2013/UITM/SKK02/5). The authors would like to express their gratitude to Ministry of Education, Malaysia and Universiti Teknologi MARA, Malaysia for financial support for this research.

\section{REFERENCES}

1. Rousseau GG, Venter DJ. Mall shopping preferences and patronage of mature shoppers. SA J Ind Psychol 2014; 40(1): 1-12.

2. Smith KB, Humphreys JS, Lenard $Y$, Jones JA, Prince $V$, Han GS. Still the doctor - by a country mile! Preferences for health services in two country towns in north-west New South Wales. Med J Aust 2004; 181(2): 91-95.

3. Khan MM, Grubner O, Kramer A. Frequently used healthcare services in urban slums of Dhaka and adjacent rural areas and their determinants. $J$ Public Health (Oxf) 2012; 34(2): 261-271.

4. McMillan SS, Sav A, Kelly F, King MA, Whitty JA, Wheeler AJ. How to attract them and keep them: the pharmacy attributes that matter to Australian residents with chronic conditions. Int $J$ Pharm Pract 2014; 22(4): 238-245.

5. Malaysia MoH. Health Facts Malaysia 2014 [cited 2015 Jan 15]. Available from: http://Vlib.moh.gov.my/cms/ documentstorage/com.tms.cms.document.Document _e09a422a-a0188549-12dd6600-

ee712d49/HEALTH\%2OFACTS\%202014. pdf.

6. Pharmaceutical Services Division Malaysia. Annual Report Pharmacy 2012 [cited 2015 Jan 15]. Available online: http://www.pharmacy.gov.my/v2/sites/default/ files/document-upload/2012-annual-report-rsz2_0.pdf.

7. Cochran WG. Sampling techniques, 3rd ed. New York: John Wiley \& Sons; 1977. $428 p$.

8. Whitehead P, Atkin P, Krass I, Benrimoj S. Patient drug information and consumer choice of pharmacy. Int $J$ Pharm Pract 1999; 7(2): 71-79.

9. Gore $P$, Madhavan S. Consumers' preference and willingness to pay for pharmacist counselling for non-prescription medicines. J Clin Pharm Ther 1994; 19(1): 17-25.

10. Khdour MR, Hallak HO. Societal perspectives on community pharmacy services in West BankPalestine. Pharm Pract 2012; 10(1): 17-24.

11. Kiran $R$, Jhamb $D$. A strategic framework for consumer preferences towards emerging retail formats. J Emerg Knowl on Emerg Market 2011; 3: 437-453.

12. Chui WK, Li SC. Advice-giving on self-medication: perspectives of community pharmacists and consumers in Singapore. J Clin Pharm Ther 2005; 30(3): 225-231.

13. Wazaify M, Shields E, Hughes CM, McElnay JC. Societal perspectives on over-the-counter (OTC) medicines. Fam Pract 2005; 22(2): 170-176.

14. Manan M, Sugumarran G, Jamil MF, Hadi MA, Long CM. Direct cost of antihypertensive drugs in a public medical centre in Malaysia. 1st Regional Health Sciences and Nursing Conference Proceeding 2011: 207-208.

15. Hanna A, White L, Yanamandram V. Patients' willingness to pay for diabetes disease state management services in Australian community pharmacies. Int $\mathrm{J}$ Pharm Healthc Mark 2010; 4(4): 339-354.

16. McElnay J, Nicholl A, Grainger-Rousseau TJ. The role of the community pharmacist-a survey of public opinion in Northern Ireland. Int J Pharm Pract 1993; 2(2): 95100. 